\title{
Chapter 5 \\ Viewpoints of Other Scientists \\ on Migration, Mental Health and PTSD: \\ Review of Relevant Literature
}

\begin{abstract}
In this chapter, we provide a review of empirical studies conducted on PTSD, mental health and wellbeing of migrants. Most studies suggest that both pre- and post-migration stressors affect the mental health and PTSD of migrants and refugees. In origin countries, trauma exposure and torture posed significant risks to migrants' mental health. Mental health issues causing significant distress for migrants in host countries include acculturative stress, legal status, family separation, language barrier, poor access to proper healthcare, discrimination, racism, feelings of helplessness, decreased self-esteem, chronic distress and hypervigilance. Among all mental health problems, depression, anxiety and PTSD are considered as most common with respective prevalent figures of 4-40\%, 5-44\% and 9-36\%. Generally, social support and adaptive coping mechanisms were identified as buffers.
\end{abstract}

\section{Introduction}

According to Pellat (n. d), for most people, the reactions to a traumatic event become less pronounced over time and may even disappear completely after a few weeks. However, if these symptoms continue for six weeks or longer, it may be a sign of PTSD. Any traumatic event can trigger PTSD, and it is important to know that PTSD is not a sign of weakness. Pellat outlined the following as the three main symptom groups of PTSD: (1) Intrusive symptoms/reexperience symptoms, (2) avoidance and blunting, and (3) hyper-arousal (excitement).

Whether you will develop PTSD may depend partly on how severe and intense the trauma was and how long it lasted. People who experience anxiety, depression or other mental disorders are more likely to develop PTSD. People who have been victims of previous trauma are also at greater risk. 


\section{Who Is at Risk for Developing PTSD?}

There are four basic rules: (1) Anyone who has been victimized can develop PTSD, (2) anyone who has seen a violent act can develop PTSD, (3) survivors of rape, domestic violence, physical assault such as a mugging or any other random act of violence can develop PTSD, and (4) survivors of unexpected events such as car wrecks, fires or terrorist attacks as well as of natural disasters such as hurricanes or earthquakes can develop PTSD.

According to Pannetier, Lert, Jauffret Roustide, and du Loûa (2017), while there exist increasingly anti-immigrant general policies and anti-immigrants social policies worldwide, which may affect immigrants' mental health (Levecque, Lodewyckx, \& Vranken, 2007; Levecque \& Van Rossem, 2015; Tinghög, Hemmingsson, \& Lundberg, 2008), there is little information on the social determinants (migration conditions and transnational ties) of men and women migrants' mental health, even though these groups are at higher risk of common mental disorders or psychological distress than natives in Europe. Using a sample of 2468 migrants in Paris, France, Pannetier, Lert, Jauffret Roustide, and du Loûa (2017) found that mental health is related to the migratory path and the migrant's situation in the host country but differently for women and men: anxiety and depression were more common with women than men because of threat to their lives in their home countries, whereas men reported poor mental health because they resided illegally in a foreign country. They also found the supportive effect of social support lowering mental health outcomes in countries of origin and of destination. Finally, they also found anti-immigrant policies and an anti-immigrant social environment in Europe causing poor mental health for immigrants.

Littlewood and Lipsedge (1989) claimed that immigrant groups are subject to discrimination in housing, employment, in education services, in everyday interpersonal relations and that virtually in all EU countries, housing of ethnic minorities indicates that they occupy the transitional zones of town areas, which are falling into disrepair and scheduled for eventual demolition in accommodation, which has rudimentary sanitation and cooking facilities. Thapa and Hauff (2005) as well as Wittig, Lindert, Merbach, and Brähler (2008) have shown that lower socio-economic status and experiencing discrimination in employment or housing are associated with a higher risk of anxiety and depressive disorders among non-European migrants.

\section{Studies on the Mental Health and Well-Being of Immigrants/Refugees}

A considerable number of studies have been carried out to examine the impact of migration stressors on mental health of migrants. Stressors encountered before departure, during the journey and difficulties associated with integration and settlement all have significant influence on poor mental health outcomes in migrants (Ottisova et al., 
2016; Williams \& van der Merwe, 2013; Ba \& Bhopal, 2017). Using cohort study data, Bryant et al. (2018) established that both pre- and post-migration stressors were significantly associated with higher levels of PTSD among refugees. Outcomes of path analyses further indicated that PTSD levels of refugee parents/caregivers were related to harsh parenting which in turn influenced children's conduct problems, emotional symptoms, peer problems and hyperactivity.

Paredes (2017) showed that stressors and mental problems experienced by immigrant communities may vary. While documented immigrants are laden with trauma and acculturative difficulties, undocumented immigrants show feelings of helplessness, decreased self-esteem, chronic distress, depression, anxiety and hypervigilance. For undocumented immigrants, hypervigilance and concealing of current status pose significant risk to their mental health (Paredes, 2017). Unfortunately, the mental health condition of irregular or undocumented migrants is likely to worsen given that they don't present themselves for physical and mental health care for fear of deportation (WHO, 2018a). In addition, the consequences of these stressors may be more profound on immigrants and refugees living with HIV/AIDS infection (IRPLWHAs). In an exploratory study, Wong, Li, Poon, and Fung (2013) showed that IR-PLWHAs suffer economic and social marginalization, stigma and discrimination which are closely connected to their gender, race, sexualities, citizenship, HIV status, and social class.

Although, studies show that immigrants suffer mental health problems as a consequence of migration experience, a more recent study revealed that mental health problems in immigrants were significantly lower compared to natives in the US, and that migrants are less likely to originate from families with mental illness (Salas-Wright, Vaughn, Goings, Miller, Chang, \& Schwartz, 2018). These findings seem to confirm the healthy migrant hypothesis. Another surprising finding is that mental health of migrants seems to equal that of host populations at arrival but overtime suffers deterioration after five years of resettlement (WHO, 2018b). This decline may be due to poor social integration with special reference to unemployment problems (Bogic, Njoku, \& Priebe, 2015).

Establishing the prevalence of refugee mental health has been met with varying results. In an umbrella review of thirteen reported studies, Turrini et al. (2017) found depression, anxiety and PTSD as the most common mental disorders among refugees and asylum seekers with PTSD taking the lead. Averagely, the prevalent rates for anxiety, depression and PTSD were 4-40\%, 5-44\% and 9-36\%, respectively. However, prevalence of PTSD may be higher among under-age refugees in Europe as studies have accounted for rates up to $25 \%$ (Horlings \& Hein, 2018). In a similar review by Priebe, Giacco, and El-Nagib (2016), PTSD was found to be more prevalent among asylum seekers, refugees and irregular migrants compared to mood, psychotic and substance use disorders. The authors also found out that depression was significantly associated with poor socio-economic status even after five years of resettlement in host country. Moreover, Silove, Ventevogel, and Rees (2017) indicated that while exposure to torture emerged as strongest predictor of PTSD, depression appeared to be strongly predicted by aggregate number of trauma events suffered. 
According to $\mathrm{Ki}$ and Jang (2018), immigrants experience adversity and hardship in a new environment. These experiences negatively affect their psychological wellbeing. Ki and Jang also reiterated that online support forums are preferred channels to seek and receive social support for mental health issues among immigrants. This research analyzed online support forums for Chinese and Korean immigrant women, focusing on different types of mental health problems, support-seeking strategies used, social support received and the relationships between them. Asian immigrant women with mental health problems primarily sought social support by sharing their personal experiences and received informational support "most". Informational support was most frequently offered for depression, anxiety disorder, and personality disorder, but emotional support was most frequently provided for impulse control. Findings further revealed that while informational support was most commonly offered with requests for information, emotional support was most repeatedly reported for statements of extreme behavior of immigrants.

In a report investigation by Matlin, Depoux, Schutte, Fiahault, and Saso (2017), which provided a summary of the current state of knowledge regarding the health issues of migrants and refugees and of the extent to which they are being met, highlighted, through a series of case studies, the diverse approaches to policies, entitlements and services provided in different jurisdictions, ranging from regional (Europe) and country (Germany, Iran, Italy, Turkey, South Africa) levels to provinces and cities (Quebec/Montreal, Berlin). These provide evidence of successes and challenges and highlight areas requiring further effort, including the domains of policy, service design and delivery, education and training, research and communication. They also underscore the problem of highly neglected aspects such as mental health and the critical importance of developing cultural/transnational competence in the health professional individuals and institutions working with migrants and refugees. Results from discussions taking place in an M8 Alliance Expert Group Meeting (Rome, 23-24 June 2017) and from the literature were synthesized to develop an 'agenda of solutions.' This finding also provided a comprehensive framework, which bridges humanitarian, ethical and rights-based imperatives to provide a framework for action in tackling the health issues of immigrants and refugees.

In another empirical analysis aimed to investigates the psychosocial wellbeing of African refugees in Winnipeg, Canada, which adopted a photo voice approach, Uwibereyeho-King, Uwabor, and Adeleye-Olusae (2017) explore stressing factors for African refugees after resettlement in Canada and the strategies they adopt to cope. Furthermore, the study used a purposive sampling procedure to recruit 15 participants ( 8 women and 7 men). Participants recruited for the study took part in a three-phase process of picture taking, one-on-one interviews, and focus group discussions on the selected pictures. Thematic analysis was used to analyze the data collected from the field of study. Identified stressors in the study included social relationship ruptures, lack of understanding of the new culture, unemployment, and navigating unfamiliar laws and regulations. Coping strategies and recommendations 
for policies and best practices were discussed in the study. However, UwibereyehoKing et al. (2017) suggest that mental health programs would particularly do a better job if they build on the cultural capital and the resilience of refugees rather than perceiving them solely as traumatized individuals in a foreign land.

Ahmed and Rasmussen (2019) in a study aimed to determine the changes in social status and post-migration mental health among West African immigrants, identified relevant social status indicators, but these indicators are not sufficient to address changes that are uniquely relevant to immigrants. The study also aimed to identify social status indicators that change during the process of migration and to examine their association with distress using variable- and person-centered analyses. The study used data from an archival dataset of West African immigrants in New York City. Pre- and post-migration changes across work, marriage, language use, urbanism, and residency status were used to assess whether positive, negative, or no change in social status had occurred in the study. Findings revealed that changes in social status indicators across migration were predicted to account for variance in mental health outcomes (i.e., anxiety, depression, somatization, and posttraumatic stress) beyond remigration potentially traumatic events (PTE). In addition, several social status indicators predicted wellbeing in this population and accounted for variance in distress beyond pre-migration PTEs. The study using Ward's method of clustering suggested that three distinct social status profiles were characterized primarily by changes in work and marriage. The cluster with the greatest positive changes in work was almost all female and had the highest depression scores. These findings suggest that the impact of change in social status across immigration is not uniform across social status indicators. Additionally, changing gender roles across migration appear to have an influential impact on post-migration social status and mental health among immigrants.

Research conducted by Polonsky, Ferdous, Renzaho, Waters, and McQuilten (2018) to explore the factors leading to health care exclusion among African refugees in Australia using blood donation as a case study. The study used a sample of 317 Australian-based African refugees, Polonsky et al. (2018) examined how refugees' acculturation, perceptions of discrimination, past behavior, objective knowledge, and medical mistrust affect African refugees' health inclusion, depending on their blood donation intentions. The findings indicate that perceived discrimination and objective blood donation knowledge directly affect donation intentions. However, perceived discrimination mediates the relationships between acculturation and intentions and between medical mistrust and donation intentions, and objective knowledge mediates the relationship between past behavior and donation intentions. Therefore, the authors offer recommendations to policy makers designing social inclusion programs and health service providers designing and delivering targeted initiatives, to better facilitate refugee participation in host country health systems.

As reported above, Pannetier, Lert, Jauffret Roustide, and du Loûa (2017) find that migrants are at higher risk of common mental disorders or psychological distress than are natives in Europe. However, little is known regarding the social determinants of migrant mental health, particularly the roles played by migration conditions and transnational practices, which may manifest themselves in different ways for men and 
for women. The aim of their study was to understand the gendered roles of migration paths and transnational ties in mental health among sub-Saharan African migrants residing in the Paris, France, metropolitan area. This study used data information from the Parcours study conducted in 2012-2013, which employed a life-event approach to collect data from a representative sample of migrants who visited healthcare facilities. Pannetier et al. (2017) measured anxiety and depressive symptoms at the time of data collection with the Patient Health Questionnaire-4 (PHQ-4). Reasons for migration, the living conditions in the host country and transnational ties after migration were considered by gender and after adjustment. The study demonstrates that among subSaharan African migrants, mental health is related to the migratory path and the migrant's situation in the host country but differently for women and men. Among women, anxiety and depressive symptoms were strongly related to having left one's home country because of threats to one's life. Among men, residing illegally in the host country was related to impaired mental health. For both women and men, crossborder separation from a child less than 18 years old was not independently associated with anxiety and depressive symptoms. In addition, social and emotional support from relatives and friends - both from the society of origin and of destination-were associated with lower anxiety and depressive symptoms. Migrant mental health may be impaired in the current context of anti-migrant policies and an anti-immigrant social environment in Europe. The study however has some limitations. First, the survey was conducted in the greater Paris metropolitan region. Thus, the results may not be generalizable to other regions. However, $60 \%$ of the sub-Saharan migrants who reside in France are concentrated in this region that accounts for $18 \%$ of the French population. ${ }^{1}$ The sample used in the study was representative of migrants who visited healthcare facilities in this region, and it is sufficiently large and diverse to represent as closely as possible the population of sub-Saharan African migrants. Nonprobability sampling is more frequent in studies conducted on migrants. However, recruitment in healthcare settings may include less healthy individuals or individuals more inclined to interact with the healthcare system. The retrospective design of the study, migrants who were forcibly or willingly returned to their country of origin were not included.

Wong, Cheung, Miu, Chen, Loper and Holroyd (2017) in an empirical investigation explore the mental health of African asylum-seekers and refugees (ASR) in Hong Kong. The study explored how social determinants of health have impacted the mental health and wellbeing of African ASRs in Hong Kong. A cross-sectional survey was adopted among 374 African ASRs recruited for the study. The survey comprised sociodemographic; health status; health behaviors; and social experiences. Also, the associations between social determinants of health and depression screen were explored and multivariate regression analysis was conducted. Findings indicate that the majority of participants were 18-37 years old (79.7\%), male (77.2\%), single $(66.4 \%)$ and educated $(60.9 \%$ high school and above). Over a third $(36.1 \%)$

\footnotetext{
${ }^{1}$ https://www.insee.fr/fr/statistiques/2044745. Accessed March 26, 2020.
} 
screened positive for depression. Further findings revealed that living with family reduced the odds of a positive depression screen $(\mathrm{OR}=0.25,95 \% \mathrm{CI}=0.07-0.88)$. Those perceiving their health to be "poor" were 5.78 times as likely to be screened for depression. Additionally, those with higher scores on the discrimination scale were more likely to have positive depression screen $(\mathrm{OR}=1.17,95 \% \mathrm{CI}=1.10-1.24)$. In addition, a significant proportion of African ASRs in Hong Kong exhibits depressive symptoms. A complex interaction combining both social determinants and perceptions of health and discrimination in the host society is likely exacerbated by their ASR status. Wong et al. (2017) therefore suggests the use of community support groups or even re-examination of the family reunification laws could improve the mental health and wellbeing of African ASRs in Hong Kong.

Evidence has established that the ethnic community plays a significant role in the mental health of traumatized refugees arriving from collective societies. For instance, Dorchin-Regev and Slonim-Nevo (2019) explored the relationships between warrelated trauma and mental health separately for direct trauma exposure (i.e., events directly endorsed by asylum-seekers) and indirect trauma exposure (i.e., events endorsed by family, friends and other community members). A sample of 300 Darfuri asylum-seekers living in Israel were obtained in a cross-sectional design. In the study, hierarchical regressions were used to examine how direct versus indirect trauma exposure were associated with posttraumatic stress disorder (PTSD), depressive and anxiety symptoms and psychological wellbeing. Findings revealed that direct trauma exposure was associated with worse mental health symptoms and reduced wellbeing. In contrast, indirect trauma exposure to similar events of others was linked with fewer PTSD, depressive and anxiety symptoms and improved wellbeing. These findings offer preliminary insights into the nature of trauma and mental health in asylum-seekers from collective cultures: While trauma directly experienced by the individual is associated with increased risk for poor mental health; exposure to others' similar experiences may be associated with reduced emotional distress. The study findings have implications in terms of their potential applicability for culturally sensitive assessment and group therapy in refugees.

Sapmaz, Tannverdi, Oztürk, Gozacanlari, Ulker and Ozkan (2017) conducted a study aimed to assess early-onset psychiatric disorders and factors related to these disorders in a group of refugee children after immigration due to war. The study conducted between January 2016 and June 2016. Clinical interviews were conducted with 89 children and their families, and were performed by native speakers of Arabic and Persian who had been primarily educated in these languages and were living in Turkey. A Strengths and Difficulties Questionnaire (SDQ) that had Arabic and Persian validity and reliability was used among children and their families. Independent variables for cases with and without a psychiatric disorder were analyzed using the $\chi^{2}$ test for categorical variables, Student's $t$-test for those that were normally distributed, and Mann-Whitney $U$-test for data that were not normally distributed. Data that showed significant differences between groups who had a psychiatric disorder and on common effects in emerging psychiatric disorders were analyzed through binary logistic regression analysis. A total of 89 children and adolescents were interviewed within the scope of the study. The mean age of cases was $9.96 \pm$ 
3.98 years, and $56.2 \%(\mathrm{n}=50)$ were girls, while $43.8 \%(\mathrm{n}=39)$ were boys. Among these children, 47 (52.8\%) had come from Syria, 27 (30.3\%) from Iraq, 14 (15.7\%) from Afghanistan, and one (1.1\%) from Iran. A psychiatric disorder was found in $44(49.4 \%)$ of the children. A total of 26 children were diagnosed with anxiety disorders, 12 with depressive disorders, eight with trauma and related disorders, five with elimination disorders, four with attention deficit/hyperactivity disorder, and three with intellectual disabilities. Furthermore, it was determined that seeing a dead or injured person during war/emigration and the father's unemployment increased the risk of psychopathology. The odds ratio was 7.07 (95\% CI 1.72-29.09) for having seen a dead or injured individual and 4.51 (95\% CI 1.67-12.20) for father's employment status. The study concluded that within the context of war and emigration, these children try to cope with the negative circumstances they experience prior to migration, as well as the despair they see their parents experience.

Neto and Guse (2018) examined demographic, acculturation and adaptation factors on the mental health of Angolan migrants residing in Portugal. They reported that these factors were significantly associated with the mental health of the participants, with acculturation factors accounting for the greater variance in mental health problems of these African migrants.

Ogunbajo, Anyamele, Restar, Dolezai, and Sandfort (2018) investigated correlates of substance use and mental health outcomes in immigrant African gay and bisexual men (GBM) in the US. Their findings showed that current substance use was significantly associated to age, openness about sexual orientation, homophobic experiences in home country, forced sex in home country, current housing instability, and internalized homophobia. In addition, posttraumatic stress disorder symptoms and alcohol use were significantly associated to depression.

McCann, Mugavin, Renzaho, and Lubman (2016) investigated help-seeking barriers and facilitators for anxiety, depression and alcohol and drug use problems in young people from recently established sub-Saharan African migrant communities in Australia. Results revealed four help-seeking barriers as: stigma of mental illness, lack of mental health literacy in parents and young people, lack of cultural competency of formal help sources, and financial costs deterring access. Result also revealed being open with friends and family, strong community support systems, trustworthiness and confidentiality of help-sources, perceived expertise of formal help-sources, as help-seeking facilitators.

Thela, Tomita, Maharaj, Mhlongo, and Burns (2018) examined post-resettlement adaptation and mental health challenges of African refugees/migrants in Durban, South Africa. Help-seeking refugees/migrants $(\mathrm{N}=335)$ were examined for anxiety, depression and posttraumatic stress symptoms. Results indicated high prevalence of mental distress; $49.4 \%$ anxiety, $54.6 \%$ depression and $24.9 \%$ posttraumatic stress symptoms. The risk of depression was significantly higher among recently arrived migrants. Further analysis revealed that older age on arrival was associated with anxiety and depression. In addition, history of family separation since migration positively associated with depression and posttraumatic stress. Also, discriminatory experiences since migration independently predicted mental health outcomes. Divorced/widowed migrants were at a higher risk for posttraumatic stress. 
Nakash, Nagar, Shoshani, and Lurie (2015) examined the association between acculturation patterns and mental health symptoms among 118 Eritrean and Sudanese asylum seekers $(\mathrm{N}=118)$ in Israel. Participants' sociodemographic information including detention history, mental health symptoms, exposure to traumatic events, and acculturation pattern were analyzed to predict their mental health. Results showed that acculturation predicted depressive symptoms among asylum seekers beyond the effect of a history of detention and reports of experiences of traumatic events. Also, assimilated compared with integrated asylum seekers (in Berry's well-known terminology) reported higher depressive symptoms.

Afulani, Torres, Sudhinaraset, and Asunka (2016) investigated the association between cross-border ties - and cross-border separation-with the health of subSaharan African (SSA) migrant adults living in metropolitan France. They reported that remitting money and having a child abroad separately were associated with poor health among women. Results also indicated that remittance sending is associated with poor health only for SSA-migrants separated from their children.

Melamed, Chernet, Labhardt, Probst-Hensch and Pfeiffer (2019) conducted a study that examined resilience and mental health in a sample of Eritrean asylum seekers in Switzerland. Results indicated that mental health was understood as a binary state rather than a continuum and that trusted friends and family were responsible for recognizing and attempting to treat mental health problems. Pathways to care were potentially interrupted for asylum-seekers. Capital building, considered through the lens of social resilience, consisted of language learning, establishing of new individual- and community-level social networks, and proactive symbolic capital building through volunteering.

Wong, Cheung, Miu, Chen, Loper, and Holroyd (2017) investigated associations among socio-demographics, health status, health behaviors and social experiences. The study tested associations between social determinants of health and depression in the sample. Results revealed that more than one-third showed symptoms of depression. Perception of health as "poor" was a risk factor for depression. In addition, perceived discrimination was positively associated to depression.

Arrey, Bilsen, Lacor, and Deschepper (2016) examined the role of spirituality/religion as a source of strength, resilience and wellbeing among sub-Saharan African (SSA) migrant women with HIV/AIDS living in Belgium. Data were collected using semi-structured interviews. Results of thematic analysis showed that majority reported being more spiritual/religious since being diagnosed HIV positive. Another important finding was that participants expressed a strong belief in the power of God in their HIV/AIDS treatment and wellbeing. Prayer, meditation, church services, religious activities and believing in the power of God were identified as resources that helped them cope with HIV/AIDS.

Agyekum and Newbold (2016) explored the experiences of African immigrants' religious place making and its relationship to health and wellbeing in a sample of Ghanaians and Somalis immigrants. The study adopted a qualitative approach to analyze the major themes. Results suggested that places of worship are significant for physical health, social, emotional, spiritual, mental and general quality of life amongst immigrants. 
Crea, Calvo, and Loughry (2015) investigated differences in health-related quality of life (QoL) in a sample of urban and camp-based refugees in sub-Saharan Africa to assess the influences of both the environment and the perceived environment on refugees' health-related QoL. Their findings indicate that refugees in urban environments reported significantly higher satisfaction with overall health, physical health and environmental wellbeing than refugees living in camps. Results suggest that urban environments were associated with better physical health for refugees, compared to camp environments. In addition, refugees' perceptions of their environment, particularly feeling safe in daily life and in the home environment, as well as being satisfied with living conditions, were more strongly associated with physical health than the environment itself, whether urban or camp-based.

Khawaja, Ibrahim, and Schweitzer (2017) conducted a study that assessed the role of social relatedness in promoting mental wellbeing among immigrant learners. They completed a battery that measured social support, school connectedness, acculturation, resilience, and mental wellbeing. Results indicated that the three social relatedness factors (social support, school connectedness, and acculturation) were related to mental wellbeing. Further analyses indicated that resilience was a partial mediator for the relationship between each of the social relatedness elements and mental wellbeing. In addition, resilience significantly mediated the relationship between social relatedness and mental wellbeing.

Martinez et al. (2015) carried out a systematic review of the literature to assess and understand how immigration policies and laws may affect access to health services and health outcomes among undocumented immigrants. They found a direct relationship between anti-immigration policies and access to health services. Results also showed that these policies impacted immigrants' mental health outcomes, including depression, anxiety, and posttraumatic stress disorder.

Chen, Hall, Ling, and Renzaho (2017) assessed the moderating effect of postmigration stressors in the association between pre-migration and post-migration potentially traumatic events and stressors and mental health in a sample of 2399 humanitarian migrants in Australia. Results indicated that 762 (31\%; 95\% CI 29.433.2) had PTSD and 394 (16\%; 95\% CI 14.2-17.2) had severe mental illness. Also, pre-migration potentially traumatic events and post-migration stressors were positively associated with PTSD and severe mental illness.

Whitley, Wang, Fleury, Liu, and Caron (2016) investigated variations between immigrants and non-immigrants in: prevalence of common mental disorders and other mental health variables; health service utilization for emotional problems, mental disorders, and addictions, and health service satisfaction. They found that immigrants had significantly lower rates of high psychological distress $(32.6 \% \mathrm{vs}$. $39.1 \%, p=0.02)$, alcohol dependence $(1.4 \%$ vs. $3.9 \%, p=0.01)$, depression $(5.2 \%$ vs. $9.2 \%, p<0.01$ ), and various other mental disorders. Further analyses revealed that immigrants had significantly higher scores of mental wellbeing (48.9 vs. 47.1 score, $p=0.01)$ and satisfaction with social (34.0 vs. 33.4 score, $p=0.02$ ) and personal relationships $(16.7$ vs. 15.6 score, $p<0.01)$. In addition, immigrants had significantly 
lower rates of health service utilization for emotional problems, mental disorders, and addictions and significantly higher rates of health service satisfaction at all-time points. Asian and African immigrants had particularly low rates of utilization and high rates of satisfaction.

Smit and Rugunanan (2015) carried out qualitative research that explored how women refugees in South Africa perceived their emotional wellbeing and how they made sense of their emotions. Results indicated that perceived inability to provide financial assistance to their kin back home significantly influenced participants' emotional wellbeing.

Schubert, Punamäki, Suvisaari, Koponen, and Castaneda (2019) tested a model of help-seeking behavior among 1356 immigrants from three different ethnic nationalities. They reported past traumatic events, social network, acculturation indices, trust in services, and mental health as well as usage of mental and somatic health services. Structural equation modelling analysis was applied to analyze the data. Results indicated that past traumatic events were associated with seeking more mental health services, indirectly mediated through increased risk for mental health problems in all three ethnic groups. Also, acculturation was a significant factor for the use of mental and somatic health services only for Kurds but social networks predicted this outcome for Kurds and Russians.

Immigrants and refugees came from diverse religious and cultural backgrounds and had complex mental health-related concerns that are not currently being adequately addressed by existing services. A thematic analysis by Thomson, Chaze, George, and Guruge (2015) reported that major barriers to the utilization of mental health services include those related to the uptake of existing health information and services, those that are related to the process of immigrant settlement, and barriers related to availability of appropriate services. In this study three major barriers were reported. Lack of awareness regarding mental health issues influence how people seek help to manage mental health problems which highly leads to depression. Cultural barriers relate to: the immigrants' expectations of the healthcare provider-client relationship; stigma of mental illness and resultant reluctance to seek outside help; gender roles; and, belief in alternate practices and inadequacy of linguistically and culturally appropriate services this means that not being fluent in English or French can pose challenges to gaining access to mental health services in an English-speaking (or French-speaking) foreign country. Moreover Ambugo and Yahirun (2016) maintain that immigrants may be particularly emotionally vulnerable to the strains and benefits of providing payments or fees while staying in another country. Furthermore, they report that among socio-economically vulnerable migrants such as refugees/asylees, sending money or fees may threaten mental health by creating financial hardship. Initiatives that encourage economic stability for migrants may protect against depression. In addition, the relationship between allowance sending and major depressive episode and sadness among US legal immigrants is significant. It was, for example, confirmed by Ambugo and Yahirun (2016) that immigrants who remitted had a higher risk of major depressive episode (MDE) and sadness compared to those who did not. 
At the same time, the effect did not vary by gender and income. Among immigrants whose households remitted, the amount sent was not significantly linked to MDE. Consistently the amount remitted was significantly associated with a higher risk of sadness among humanitarian migrants compared to employment principals.

Yachouh (2018) interviewed Syrians in Canada, and revealed that a high proportion of respondents were suffering from one or more of the following: anger, fearfulness, nervousness, difficulty falling asleep or staying asleep, hopelessness about the future and spells of terror and panic. All participants of Yachouh's study considered social support as being of foremost importance in their lives, preferring it over professional help. In light of similar findings in her study, Mulugeta (2019) suggested that a community organizing can serve as a critical and irreplaceable tool for promoting health equity and that, in particular, such organizing is seen as increasingly impactful among communities that are most marginalized.

Purewal (2018) agrees that there is generally a greater mental illness among refugees. Statistics from Brooke et al. (2017) confirm this by demonstrating that 20 to $30 \%$ of asylum seekers suffer from some form of mental health issue with varying diagnoses. No effective measures or treatment has been taken to improve mental health in these individuals. This may lead to a more complicated disease image with treatment-resistant symptoms and causing somatic complications as a consequence. On contrary, Fung and Guzder (2018) state that in Canada immigrants from various countries have better physical and mental health than the general population. This has been termed the "healthy immigrant effect." Possible explanations for this include immigration criteria that select for a healthier cohort, the attributes of people who choose to immigrate or have successfully navigated the point system of entry, as well as health examination procedures that screen out those with severe mental illness such as mood disorders.

Refugees are victims of war, violence, persecution or torture who escape their home countries to seek safety in other countries. After victims of war and violence escape from their countries of origin, a large proportion of them are initially hosted as refugees in countries within the same region which affects wellbeing as a whole (Glen, Onsando, \& Kearney, 2015). A study by Ahmed (2017) indicates that Iraqi refugees suffer more mentally and physically than other immigrants, for instance African refugees who fled their countries of origin, forced to leave behind valued belongings, family members, and friends due to poverty and wars. For these refugees, attempting to adjust to a different living environment after resettling to a new country is often challenging, stressful, and anxiety provoking, particularly if their migration is a result of war or political turmoil. 


\section{Posttraumatic Stress Disorder (PTSD) of Immigrants/Refugees}

Evidence supporting the association between migration and posttraumatic stress disorder (PTSD) has been documented. Bustamante, Cerqueirra, Leclerc and Brietzke (2018) in an empirical analysis considered the growing population of migrants and the particularities of providing culturally sensitive mental health care for these persons, clinicians should be kept up to date with the latest information regarding this topic. According to Bustamante et al. (2018), the objective of their study was to critically review the literature regarding migration, trauma and PTSD, and mental health services. Migration is associated with specific stressors, mainly related to the migratory experience and to the necessary process of acculturation occurring in adaptation to the host country. Their findings revealed that these major stressors have potential consequences in many aspects, including mental health. Furthermore, the prevalence of PTSD among migrants was found to be very high (47\%), especially among refugees, who experience it at nearly twice the rate of migrant workers.

Refugee mental health has been found to be affected by traumatic stressors as well as post-migration living difficulties (PMLD) (Schick, Morina, Mistridis, Schnyder, Bryant, \& Nikerson, 2018). However, their interaction and causal pathways are unclear, and so far, no distinct treatment recommendations regarding exilerelated stressors exist. In a study aimed to assess the changes in post-migration living difficulties in traumatized refugees using a three-year follow-up study, PMLD, and symptoms of posttraumatic stress, PTS), depression and anxiety were examined in a clinical sample of severely traumatized refugees and asylum seekers $(\mathrm{N}=71)$. Schick et al. (2018) found that reduction in PMLD predicted changes over time in depression/anxiety, but not in PTS. Also, the opposite models with PMLD changes as outcome variable proved not significant for PTS, and significant, though less predictive, for depression/anxiety. In addition to well-established trauma-focused interventions for the treatment of PTS, psychosocial interventions focusing on PMLD might contribute to a favorable treatment response in traumatized refugees, particularly with regard to depression and anxiety. Therefore, Schick et al. (2018) emphasized the importance of policy makers to recognize the role of daily stressors in contributing to psychological distress and their negative impact on social integration. In addition, the interest of host societies to support aid agencies, caseworkers or settlement service providers in addition to psychological treatment were high lightened in the study.

In a study aimed to examine the recent appearance of several 'anti-heroic' memoirs of the South African 'Border War' written by conscripts, Doherty (2015) emphasized the use of the medical diagnosis of Posttraumatic Stress Disorder (PTSD) in those writings which were critically examined. According to Doherty (2018), the memoirs reveal how difficult it is to articulate memories of contemporary war without drawing on a medical explanation. The South African memoirs also demonstrate the ambiguous role that the diagnosis of PTSD plays in this, on the one hand, enabling the 
authors to speak about their experiences, whereas, on the other, providing an opportunity for them to distance themselves from the ethical implications of their own involvement in the war. Doherty (2015) asserted that the tension within the identity of victim-perpetrator is perhaps too easily collapsed into simple victimhood.

Kaoutar El Maazouz and Scruby (2019) in their study of PTSD among refugees, found that refugees are being displaced from countries around the world and seeking asylum in North America. With this development, nurse practitioners (NPs) are delivering primary health care services to a growing number of refugees who have been exposed to a multitude of different traumas and frequently suffer from posttraumatic stress disorder (PTSD). Also, NPs face numerous barriers in the provision of mental health care to refugees. This clinical feature emphasizes the importance of using cross-cultural PTSD screening tools as well as trauma-informed care to initiate open dialogue with refugee patients. The study highlights the nonpharmacological and pharmacological management of PTSD among refugees. Furthermore, Kaoutar El Maazouz and Scruby (2019) indicate that refugee populations are often exposed to pre-migration trauma and torture as well as post-migration stressors. Exposure to trauma has been found to predispose this cohort to a high degree of vulnerability and significant mental health disorders, such as PTSD, which may be present with or without somatic manifestations (Kaoutar El Maazouz \& Scruby, 2019). Additionally, refugees repeatedly seek medical assistance for vague somatic presentations and encounter difficulties with resettlement. NPs in primary care settings are often the first point of contact for refugee patients. As a result, NPs encounter difficulties when trying to cater to refugees' unique health needs (Kaoutar El Maazouz \& Scruby, 2019).

A high prevalence of post-traumatic stress disorder (PTSD) in refugee and asylum seeker populations which can pose distinct challenges for mental health professionals has been documented (Thompson, Vidgen, \& Roberts, 2018). The study adopted 16 randomized controlled trials (RCTs) with 1111 participants investigating the effect of psychological interventions on PTSD in these populations. The PsychInfo, ProQuest (including selected databases ASSIA, IBSS, PILOTS), Web of Science, the Cochrane Central Database of Controlled Studies (CENTRAL) and Cochrane Database for Systematic Reviews (CDSR) were searched by Thompson et al. (2018) to identify peer-reviewed, primary research articles up to May 2018. The current study used rigorous methods to assess the quality of included trials and evidence using Cochrane, SURE and GRADE systems. However, 525 trials were reviewed, 16 were included with 15 contributing to meta analyses. Despite the challenges of conducting research in this field, Thompson et al. (2018) found evidence for trauma-focused psychological interventions for PTSD in this population. In the process of sub-group analyses, evidence was found to support the use of EMDR and Narrative Exposure Therapy for PTSD symptoms. The findings in relation to the broader PTSD treatment literature and related literature from survivors of large-scale conflict were given focus in the study. Overall outcomes suggest that trauma focused psychological therapies can be effective in improving symptoms for refugees and asylum seekers with PTSD. 
Cengiz, Ergun and Cakici (2019) carried out an empirical analysis to investigate the relationship between posttraumatic stress disorder, posttraumatic growth and resilience in Syrian refugees. 310 Syrian refugees living in the Reyhanlı district of Hatay were recruited for the study. Measures such as Demographic Information Form, Impact of Events Scale, Harvard Trauma Questionnaire Section I, PostTraumatic Growth Inventory and Connor-Davidson Resilience Scale were used to gauge responses from the participants. Findings indicate that the rate of PTSD was $80 \%$. Low monthly income and wishing to return to their home country were found to be risk factors for PTSD. Also, findings revealed that refugees with PTSD had higher war-related traumatic events. In addition, posttraumatic growth was higher among refugees with PTSD, particularly in the areas of relating to others and spiritual change. Afterwards, resilience and posttraumatic growth were found to be positively correlated, and regression analysis showed that resilience promotes posttraumatic growth. The study suggested that posttraumatic growth can be increased by strengthening the resilience of Syrian refugees.

In similar vein, studies have established that thousands of minor refugees entered Europe (Horlings \& Hein, 2018). This group has been exposed to traumatic events pre-, mid-, and post-migration and is at increased risk of developing psychiatric disorders. In Horling and Hein's study, results of literature search on screening and interventions for PTSD in minor refugees were explored, in order to make recommendations for clinical practice. Findings indicate that studies on diagnostic accuracy of assessment instruments and efficacy of mental healthcare interventions in this population are lacking. In addition, traumatic experiences pre-flight, during the flight and at resettlement, superimposed by parental PTSD, and other contextual factors, might lead to more than $25 \%$ of minor refugees developing PTSD. Horlings and Hein (2018) are of the opinion that in enhancing the number of minor refugees recognized with PTSD, the use of a brief screening instrument is advisable. Hence, a public health approach, focusing on environmental supportive factors is the first step in treatment for this group, followed by short-term psychological group interventions focusing on psycho-education and stress reduction. Furthermore, minor refugees with no improvement in PTSD symptoms by these interventions need referral to specialized mental health care services.

Empirical evidence has confirmed that refugees often experience high levels of trauma and overall stress that contribute to disproportionate risk for mental health problems (McDonald, Hyoyin, Green, Luce, \& Denise, 2019). In view of a $136 \%$ increase in the number of Somali refugees over the past quarter century, culturally appropriate mental health screening and assessment instruments for use with this population remain limited (McDonald et al., 2019). In their study, multidimensional item response theory was used to compare structural models and validity of the Posttraumatic Stress Disorder (PTSD) Checklist-Civilian Version. Data were collected from a purposive sample of 250 Somali youth living in Nairobi's Eastleigh Estate in Kenya. Using ConQuest software, McDonald et al. (2019) used the multidimensional extension of the Rasch model to test seven competing models of PTSD in this sample. The four-factor emotional numbing model of PTSD provided the best fit for the data; there was no differential item functioning by sex or country of birth. The study, 
however, found support for convergent validity, and canonical correlations generally supported theoretically expected relationships between PTSD Checklist-Civilian Version subscales and mental health and trauma-related measures. Identification of numbing, as a dimension distinct from effortful avoidance, permits a more refined determination of PTSD in this population. This finding can guide the development and implementation of targeted interventions.

In a study by Reavell and Fazil (2017), a high incidence of PTSD and depression were found in refugee minors and poorer mental health was correlated with increased exposure to violence. Factors such as social support and family security were identified in reducing the rates of PTSD and depression, whereas the implications of age and gender were unclear. It was also found that long-term effects from these mental illnesses indicated scholastic issues, but no further worsening of symptoms. However, Reavell et al. (2017) emphasized that further research will be needed regarding the follow-up of refugee minors with PTSD and depression to allow the establishment of more effective support systems, as long-term outcomes become more clearly understood. Also, only few studies discuss the influence of religion, which may be an interesting line of future research as refugees move to more secular societies than their home countries.

In another research conducted by Daphe and Ferszt (2019), to investigate migration experiences of Sierra Leoneans in West Africa. The country entrenched in an 11year civil war characterized by widespread atrocities between 1991 and 2002, which significantly impacted thousands who are hunted with deep psychological wounds. According to Daphe and Ferszt (2019), the civil war resulted in nearly 70,000 casualties, and millions were displaced in Sierra Leone. This study used a qualitative approach to inquiry. Twelve semi-structured interviews were conducted with adults who emigrated from Sierra Leone to the United States after the civil war. From the study, findings are categorized under five categories: casualties of war; reasons for migration; acculturation; psychological impact; strength and resilience. Understudied African immigrant populations may experience nuanced challenges when migrating to another country. Participants in this study faced numerous challenges, they also exhibited a prominent amount of strength and resilience.

Plener, Groschwitz, Brähler, Sukale and Fegert (2017) in a study aimed to assess attitudes of the general population towards vulnerable groups in Germany, provided that in Germany an increase in numbers of refugees in 2015 with nearly a third being below the age of 18 occurred. Among the latter, unaccompanied refugee minors (URMs) present an especially vulnerable group. In addition to pre-flight and flight stress, the acculturation process can work as potential stressor. Plener et al. (2017) conducted a study in a representative sample $(\mathrm{N}=2524)$ of the German population (ages 14 years or older) between January and March 2016. Findings revealed that only $22.8 \%$ of participants thought that Germany could accompany URMs more. While few participants argued in support of immediate deportation of URMs in general $(38.6 \%)$ or of URM from the Middle East $(35.3 \%)$, a majority advocated for immediate deportations of URM from the Balkan region (62\%) or from Africa $(51.1 \%)$. Differences in the variance regarding attitudes towards deportation was explained mostly by right-wing political attitudes as well as by islamophobia attitudes 
and general rejection of asylum seekers. The study also confirmed that there were high rates of approval for guaranteeing the same chances to schooling or apprenticeships for URMs, as to German children and for bestowing URMs with a right to permanent residence if they were able to complete school or apprenticeship. Education and qualification are two important factors to integration. Studies about needs and wishes of URMs consistently report a high motivation to learn the language of their new host country and attend school. At this point, hopes of URMs and expectations of society underlines the importance of participation in education as key factor in integration (Plener et al., 2017).

Research has revealed that the perceived uncontrollable nature of-rather than the exposure to-torture, influences the development of psychological disorders (Le, Morina, Schnyder, Schick, Bryant, \& Nickerson, 2018). Perceived distress during torture has also been shown to influence psychological outcomes. In a crosssectional study, which explored the relationship between perceived torture controllability, emotions (i.e., anger and fear) during torture, and current posttraumatic stress (PTS), depression and anger symptoms, controlling for the effects of post-migration living difficulties, using 108 refugees and asylum seekers in treatment at two psychiatric clinics in Zurich, Switzerland. Path analyses revealed negative correlations between PTS, depression and anger symptoms, and perceived torture controllability, and positive correlations with anger and fear during torture. Furthermore, the effects of perceived torture controllability on PTS and depression symptoms were mediated by fear during torture, and on anger symptoms via anger during torture. This was over and above the effects of post-migration living difficulties on psychological symptoms. The study provides preliminary evidence that perceived uncontrollability and distress during torture might be significant risk factors for current mental health of torture survivors.

High rates of PTSD have been well-documented among refugees, however no study has investigated the heterogeneity of DSM-5 PTSD symptomatology in such populations (Minihan, Liddell, Byrow, Bryant, \& Nickerson, 2018). Therefore, Minihanet al. (2018) investigated a study aimed to determine whether there are unique patterns of DSM-5 defined PTSD symptomatology among refugees, and investigate whether factors characteristic of the refugee experience, including trauma exposure and post-migration stress, predict symptom profiles. Participants were 246 refugees and asylum-seekers recruited from an Arabic-, English-, Farsi-, or Tamil-speaking background who had been resettled in Australia. Participants were asked to complete measures of post-migration living difficulties, trauma exposure, PTSD symptoms and functional disability. The study employed the use of latent class analysis to identify PTSD symptom profiles, and predictors of class membership were elucidated via multinomial logistic regression. In the findings, four classes were identified: a high-PTSD class (21.3\%), a high-re-experiencing/avoidance class (15.3\%), a moderate-PTSD class (23\%), and a no PTSD class $(40.3 \%)$. Trauma exposure and post-migration stress significantly predicted class membership and classes differed in degree of functional disability. The study employed a cross-sectional design, which precluded inferences regarding the stability of classes of PTSD symptomatology. It does, however, provide evidence for distinct patterns of PTSD symptomatology in 
refugees. Furthermore, the study identified a novel class, characterized by high-reexperiencing and avoidance symptoms, as well as classes characterized by pervasive, moderate, and no symptomatology. Trauma exposure and post-migration stress differentially contributed to the emergence of these profiles. Individuals with high and moderate probability of PTSD symptoms evidenced substantial disability. These results support conceptualizations of PTSD as a heterogeneous construct, and highlight the importance of considering sub-clinical symptom presentations, as well as the post migration environment, in clinical contexts (Minihanet al., 2018).

Kashyap, Page, and Joscelyne (2019) used archival clinical data to identify post-migration correlates of reductions in distress among torture survivors, after accounting for pre-migration trauma. Participants were assessed for depression and PTSD following six months of interdisciplinary treatment. Relationships between pre-, post-migration factors, and changes in symptom levels from intake to six months' follow-up were evaluated. Results indicated that average levels of depression and PTSD significantly reduced after six months of treatment. Result showed further that higher exposure to pre-migration trauma, female gender, and change to a more secure visa status were associated with reduced distress. In addition, the findings showed that accessing more social services and not reporting chronic pain were associated with reduced PTSD.

Ziersch, Due and Walsh (2018) examined the impact of discrimination relating to skin color, ethnic origin, or religion experienced by asylum seekers and refugees on health, wellbeing and settlement outcomes. The following results were obtained: participants reported experiencing discrimination related to physical assault, denial of services and insults and offensive behavior; experiencing discrimination was associated with less sense of belonging $(p<0.01)$, lower levels of trust $(p=0.04)$, reduced sense of control $(p=0.01)$ and less hope for the future $(p<0.01)$. Further analyses revealed that those who experienced discrimination self-perceived that it negatively affected their health, and also had significantly worse mental health $(p<$ $0.01)$. Participants varied in their responses to discrimination: Whereas while some perceived that it led to negative emotional outcomes such as stress or anxiety, others discountenanced its impact.

Wu et al. (2018) examined the relationship between Berry's acculturation patterns (i.e., integration, assimilation, separation and marginalization) and mental health of migrant youth. The study also investigated whether resilience mediated in the relationship between acculturation and mental health. Result showed that resilience scores correlated strongly with mental health and wellbeing. There were no significant direct effects of acculturation on participants' mental health. Also, integrationoriented participants exhibited lower levels of resilience, and (sic!) poorer mental health compared to assimilation-oriented youths.

Jannesari, Molyneaux, and Lawrence (2019) investigated how people seeking asylum make sense of their migration experience and the factors impacting the mental health and wellbeing of asylum seekers in the UK. Results revealed seven themes that negatively impacted their wellbeing after analysis; dehumanization due to the asylum 
process and public discourse; continued experiences of torture and lack of control in the UK; the asylum process inhibited people reconciling their pre-migration trauma and from planning for their future and consequent loss of identity.

Toselli, Rinaldo, Caccialupi, and Gualdi-Russo (2018) investigated psychosocial health and quality of life in a sample of 205 North African immigrant women living in Italy. After analyzing the data, results showed that significant association between psychosocial status and migrant status. Additional analysis revealed that educational level and number of children were associated with psychological discomfort, weight status associated with wellbeing while quality of life significantly associated with stress. The authors concluded that the results were evidence of higher psychological stress and discomfort and lower wellbeing and quality of life in immigrant women.

Research have also shown that immigrants enter their new countries with higher levels of mental health, but this health advantage soon deteriorates after immigration. Many authors (Craig, Jajua, \& Warfa, 2009; Falah-Hassani, Shiri, Vigod, \& Dennis, 2015; Purewal, 2018; Thomson, Chaze, George, \& Guruge, 2015) link the deteriorating mental health to myriads of obstacles ranging from experiences during pre-migration, the departure process, the post-arrival and environment. A majority of the refugees has experienced severe pre-migration trauma, mental and physical torture, mass violence and genocide, witnessing the killings of family members and friends, sexual abuse, kidnap of children, destruction and looting of personal property, starvation and lack of water and shelter. In the view of Fung and Guzder (2018), immigrants, refugees and asylum seekers are likely to be susceptible to mental disorders because of traumatic events they encounter prior to immigration and adverse circumstances in the new country. Others (Dwivedi, O'Donnell, \& Jankowski, 2019; Salfi, 2016; Staudenmeyer, Macciomei, Del Cid, \& Patel, 2016) recognize that inability to access proper medical health care in the host country affect immigrants' mental health and wellbeing.

Craig, Jajua and Warfa (2009) agree that immigration is a complex process that is accompanied with life threatening risks. Migrants' perception is that the arrival in the host country is expected to provide relief, but frustration develops as new problems emerge in the new country. Problems like family separation, language challenges, legal status, employment issues, poor shelter or homelessness, or lack of access to proper healthcare and education become evident. Stenmark et al., (2013) explain that the circumstances and experiences of forced migration have potential to negatively affect refugees' health and integration into the host society notably, migrants who escape their countries because of armed conflicts and persecution are more likely to report high rates of pre-migration trauma and high frequencies of mental health problems, particularly PTSD and depression. For example, the case of the armed conflict in Syria in 2011 resulted in the forced displacement of five million Syrian population (UNHCR, 2017), over 50\% being children, many unaccompanied (UNICEF, 2016).

In addition, post-migration experiences also affect mental health and migrant wellbeing. For example, studies (Fung \& Guzder, 2018; Purewal, 2018) have shown that asylum seekers report higher rates of PTSD and depression than other refugees. Such mental ill health is unearthed by post migratory stresses, delay of permits, 
conflicts with immigration officials, unemployment, and separation from families. Besides, forced migrants frequently arrive in places without family ties, no contacts and or knowledge of the language which contribute further to increased isolation and limited opportunities.

In Sweden, Purewal (2018) explored different types of mental ill health among immigrant/refugees, factors that affect psychological ill health and association between mental disorders observed in refugees and the factors responsible for them. Findings indicated depression, PTSD, anxiety and somatization are common diagnoses among refugees. Further results revealed that many refugees experienced traumatic events while in their home country and during escape. Unfavorable situations such as violence, killing, food scarcity, bad shelter and lack of money affect their mental health negatively. While arrival in the new country may be expressed in joy, such joy is often short-lived because of resettlement challenges like language difficulties, discrimination, unemployment, separation from family and culture.

The above finding was replicated for Syria, when Yachouh (2018) interviewed 30 Syrian immigrants to the US (15 non-refugees and 15 refugees) with the aim of investigating perspectives on mental health, resilience, and desired or received services. Results indicated that refugees' mental health was affected by traumatic events and their resettlement process. Non-refugees expressed feelings of unhappiness because their homeland has been destroyed.

Nakash, Nagar, Shoshani and Lurie (2015) examined the association between acculturation patterns and mental health symptoms among 118 Eritrean and Sudanese asylum seekers in Israel. An association was found between acculturation and mental health, in that, acculturation predicted depressive symptoms among asylum seekers more than the effect of history of detention and reports of experiences of traumatic events. Additionally, assimilated compared with integrated asylum seekers reported higher depressive symptoms.

Two years after, Nakash, Nagar, Shoshani and Lurie (2017) investigated the combined effect of exposure to traumatic events and perceived social support on PTSD symptoms among 90 male asylum seekers in Israel. It was noted that, majority of the participants were exposed to traumatic events, they lack good shelter, they suffer from ill health without access to medical care, from imprisonment and tortured. Results indicated that perceived social support was associated with lower PTSD symptoms only for those who reported low exposure to traumatic events. Among asylum seekers who reported high exposure to traumatic events, social support did not affect the association between exposure to traumatic events and PTSD symptoms. It was found that perceived social support serves as a significant moderator in the relationship between exposure to traumatic events and PTSD symptoms among asylum seekers, depending on the severity of exposure to traumatic events. The complex relationship between protective factors such as perceived social support, exposure to trauma and mental health should inform mental health services for forced migrants.

Falah-Hassani, Shiri, Vigod, and Dennis (2015) compared the prevalence of postpartum depressive symptoms between immigrant women and non-immigrant women, and determine risk factors for postpartum depressive symptoms in immigrant women. By means of meta-analysis, 24 studies were included in the analysis. 
It was found that immigrant women were twice more likely to experience depressive symptoms in the postpartum period than non-immigrant women. Risk factors associated with postpartum depressive symptoms among immigrant women included shorter length of residence in the destination country, lower levels of social support, poorer marital adjustment, and perceived insufficient household income

Among 135 Somalia young refugees in the US, Lincoln, Lazarevic, White and Ellis (2016) investigated the relationships among acculturation styles and hassles and wellbeing, also investigating the role of gender. The findings revealed that in addition to trauma history, acculturative hassles and acculturation style impact the wellbeing of these refugees. These findings indicate the need to understand both past experiences and current challenges.

Shoshani, Nakash, Zubida and Harper (2016) examined differences between groups in school engagement, mental health symptoms, and risk behavior. Participants were 448 Israeli students, 128 non-Jewish 1.5 generation migrant adolescents (migrant children living in Israel, about one quarter of African origin), 118 secondgeneration migrants (migrant children born and living in Israel), and an age-matched sample of 202 native-born Jewish adolescents. Findings showed higher levels of mental health symptoms and risk behaviors among 1.5 and second-generation migrant adolescents compared with native-born adolescents, no significant differences were found between 1.5 generation and second-generation migrants. In addition, there was association between migrants' age and gender and mental health symptoms as well as risk behaviors - older participants engaged in more risk behaviors and females had elevated mental health symptoms. Lastly, identification with the host country mediated between school engagement and mental health symptoms $(p<0.01)$ and risk behaviors $(p<0.01)$ in 1.5 generation and second-generation migrants, respectively.

Using a review framework in Canada for the purpose of exploring the gaps and opportunities for improving access to mental health services, Thomson, Chaze, George and Guruge (2015) found that the major barriers to the application of mental health services are barriers related to existing health information and services; process of immigrant settlement; and those related to availability of appropriate services. Fung and Guzder (2018) aver that immigrants often underutilize mental health services until their illness deteriorate, linking this to multiple access barriers. In addition, Fung and Guzder (2018) examined 'healthy immigrant effect' and found that, some immigrants physical and mental health deteriorate as a result of acculturative challenges and the impact of social determinants of health. The authors recommend that to improve mental health of immigrants, there is a need to address social inequities in host countries, besides problems of oppression, reflected in the higher unemployment and underemployment rates, poverty, racism, discrimination, and the culmination of intersectional marginalization should also be taken into consideration.

Finally, Staudenmeyer, Macciomei, Del Cid and Patel (2016) advocate for a broader collaborative approach towards treatment for immigrant youths because of the expected risk to physical and psychological health issues because of the relationship between previous trauma exposure and stressful experiences in the host country. In the US, providers caring for immigrant youth and their families need to 
be well versed in strategies to reach, build trust, and promote access to care for this population (Dwivedi, O’Donnell, \& Jankowski, 2019).

Depression, PTSD, anxiety and somatization are common diagnoses among refugees. Many refugees experienced traumatic events in their home country and during escape. Unfavorable conditions like violence, murder, lack of food, shelter and lack of money affect their mental health negatively. Landing in a new country can be expressed in joy, but it does not stay for a long time with upcoming resettlement difficulties such as communication problems, discrimination, unemployment, separation from family and culture (Purewal, 2018). Moreover, PTSD diagnoses in Syrian refugees should be flagged in particular for females, refugees that faced two or more traumatic events, and socio-demographic features such as personal and family history of psychiatric disorder (Ibrahim \& Hassan, 2017). Basheti, Obeidat, and Reddel (2017) reported that there are differences in the standard of care delivered to refugees at the camp in Jordan, suggesting that the situation needs to be re-evaluated based on the increase of refugees and that a dedicated paramedical team is required to assess the needs and coordinate them as they emerge to reduce the level of PTSD.

For PTSD and major depression, often linked to torture experiences and exposure to trauma as a result of conflict in their home countries, mental health issues are often exacerbated by resettlement stressors such as unemployment, poor housing and social isolation due to language and cultural barriers and discrimination as seen in the press (Jefferies, 2018). Turrini et al. (2017) established that some people within asylum seeker and refugee populations may struggle with high rates of psychiatric illness. Therefore Jefferies (2018) suggests that not only are the healthcare services which serve these populations severely under-resourced, but also there are significant barriers to effective healthcare for asylum seekers and refugees as a result of cultural disparities between these service users and UK healthcare providers, which can only be resolved through substantial educational interventions amongst asylum seekers, refugees and healthcare services, without the education-focused approach, combatting the growing cultural, economic and health disparities between the indigenous population and the population of asylum seekers and refugees within the UK may be impossible.

Duggleby et al. (2017) stated that an individual who objectively experienced less direct persecution prior to fleeing but upon arrival in a new country experiences xenophobia or racism could have a worse long-term scenario than someone who experienced more direct violence in the country from which they fled but has a more positive post-persecution experience. Moreover in the South African perspective, foreigners are often viewed as 'stealing jobs,' and the idea is widespread that migrant entrepreneurs pose a threat to South African-owned spaza shops, a myth that has consequences, namely that these immigrants are likely to suffer from PTSD because of the street attacks experienced (Nel, 2018).

In addition to the nature and extent of posttraumatic stress among refugees and migrants in Western countries, Mhlongo, Tomita, Thela, Maharaj, and Burns (2018) reported for female Africans migrating within Africa that greater numbers of traumatic life events experienced by them were associated with raised odds of posttraumatic stress disorder, and exposure to sexual trauma events were associated with 
greater odds of posttraumatic stress disorder, also. Therefore the critical importance of mental health service for females with history of sexual traumatic events for this vulnerable population.

\section{Demographics, Migrants/Refugees, Migration and Trauma}

Unfortunately, risk factors for gender and wellbeing of African migrants are unknown. According to Marshall (1995), gender refers to socially constructed aspects of differences between men and women. Since its introduction as a social concept, it has been extended to refer not only to individual identity and personality but also, the symbolic level, to cultural ideas and stereotypes of masculinity and femininity.

On demographics, Pratchett, Pelcovitz, and Yehuda (2010) suggest sex differences in both prevalence and duration of PTSD. PTSD as a response to trauma is repeatedly found to be more common among women than men (Benedek \& Wynn, 2011; Idemudia et al., 2013). Pratchett et al. (2010) also add that women typically experience PTSD symptoms for longer periods than men. Sexual assault is one of the most severe traumatic experiences and has a significantly higher incidence in women. This greater life time exposure to sexual assault among women may explain the higher prevalence of PTSD in women despite the lower overall exposure to traumatic events. Overall, it remains unclear whether there is a "true" gender effect that moderates PTSD risk or instead the increased PTSD risk in women is explained by environmental factors such as the type of trauma.

Mabeya (2017) reported that the "Lost Boys," Sudanese refugees boys who relocated to the US assisted by the US government as a result of intensely bloody and protracted warfare in their home country then known as Sudan had a bad experience in the US because of their education level. Kagaba (2018) stated that in adjustment to the host country, these immigrants or refugee parents engage in social exchanges, such as with other immigrants or refugees, and resettlement program workers that can self-identify in terms of class, gender, sexual orientation, race and ethnicity, the parents simultaneously utilize their own pre-existing gender boundary negotiation strategies. For instance, parents who used to deal with tribal or religious differences in their homelands are expected to navigate a social context characterized by cultural norms and mores based on their own tribal and/or ethnic differences, various experiences during their displacement, national differences with other immigrant or refugee communities, and the US culture by doing that they engage in bridging multiple simultaneous transnational cultural gaps to the host country. Van der Ven et al. (2016) maintained that psychosis risk among migrants from the Maghreb appears a consistent, foremost among the Moroccan-Dutch: Men from the Maghreb had a significantly higher risk than their European counterparts. In contrast, incidence rates of non-affective psychotic disorder (NAPD) for women from the Maghreb were, with one exception, similar to those for non-migrant women in Europe. Idemudia (2018) 
report that children who are immigrants are often not hostile to differences because xenophobic tendencies are usually tied to negative stereotypes that exist among adults in the host country.

\section{Education}

Education is a key aspect of refugee children's social and emotional rehabilitation and healing Kovinthan (2016) revealed that there are gaps in beginning teachers' knowledge about who refugees are, their experiences, and how best to support them in the classroom. Some teachers also held negative attitudes vis-à-vis refugee students and failed to develop a nuanced perspective of diversity and multiculturalism. Furthermore, the study showed how narrative inquiry, in the form of a personal history account, can be used as tool to surface, challenge, and overcome negative stereotypes, biases, and assertions that prevent teachers from effectively supporting their students. Barber and Ramsay (2017) suggest that teachers have a critical role in the schooling experience of refugee students, as the values and attitudes expressed by teachers impact students' sense of belonging within the learning community. Teachers are often responsible for identifying the unique challenges and needs of refugee students resulting from possible traumatic experiences in the pre-migration and migration periods; they are also expected to provide the necessary support to these students in the classroom and school.

\section{Religion}

Most significantly, the controversy around the Cologne events ${ }^{2}$ immediately authorized public debates over how recently arrived refugees and migrants could be expeditiously rendered deportable and promptly expelled. The rather selective logic of antiterrorist suspicion that had been mobilized for the purposes of more stringent (external) border enforcement, once confronted within the European interior with the palpable presence of recent arrivals of "Muslim" refugees and migrants, was promptly re-purposed as a considerably more expansive problem of internal law enforcement, emphatically conjoined to arguments for new powers to unceremoniously deport allegedly criminal asylum seekers (De Genova, 2018).

\footnotetext{
${ }^{2}$ On New Year's Eve 2015/16 numerous sexual assaults took place during public celebrations in Cologne (and a number of other German cities), and were accredited to "Arab and North African" perpetrators by the public; https://real-life-villains.fandom.com/wiki/2015-16_New_Year\%27s_ Eve_sexual_assaults_in_Germany. Accessed March 26, 2020.
} 


\section{Discrimination and Language}

Discrimination, particularly racial discrimination has been known to exacerbate psychological dysfunctions among migrants in Europe (Idemudia \& Boehnke, 2005, 2006; Idemudia, 2006). According to Fernando, (1993), racism is the most serious risk factor for immigrants. Other researchers (Ataca, 1996; Furnham \& Shiekh, 1993; Vega et al., 1993; Ward \& Chang, 1997) have also found negative correlates of perceived discriminations or prejudice and psychological wellbeing.

Access to mental health and wellbeing are directly related to discrimination among African migrants in Germany (Idemudia \& Boehnke 2010). When African migrants come to Europe, they are faced with language challenges. Gorman, Brough and Ramirez (2003) found out that people who come from a non-English-speaking background (NESB) are disadvantaged in terms of access and quality of service in Australian monocultural Anglo-Celtic health setting, Australia supposedly being an officially acknowledged multicultural society. LoGiudice et al. (2001) have earlier also made a similar observation that due to absence of sensitivity and understanding, young people and all culturally and linguistically diverse (CALD) clients do not have access to mental health services. Some researchers (Blackford et al., 1997, Comino et al. 2001) have claimed that such clients do not have access to mental health services and are at risk of poor or even destructive experiences when they do access them.

\section{Coping Mechanisms and Migrants' Adaptation}

It is substantially documented in the research literature that refugees and migrants are a highly vulnerable population experiencing many difficulties and stressors in their sojourns for a safe haven (Meyer-Weitz, Asante, \& Lukobeka, 2018; Idemudia et al. 2013; Bustamante et al., 2018). Given that the migration process is accompanied with a myriad of stressors, trauma and psychological difficulties, it is necessary to understand the strategies adopted by migrants to cope with these problems in order to prevent exacerbation of associated mental health problems. Coping with life stressors involves constant change in individual cognitive and behavioral efforts at dealing with pressures exceeding personal resources and abilities (Lazarus \& Folkman, 1984).

As earlier indicated in Chapter Four under theories, researchers usually categorize ways of coping as adaptive/maladaptive, primary/secondary control coping, problem/emotion focused, engagement/disengagement, and approach/avoidance (García, Barraza-Peña, Wlodarczyk, Alvear-Carrasco, \& Reyes-Reyes, 2018).

Studies have examined coping strategies used by migrants in ameliorating the effect of stressors. Banyanga, Björkqvist and Österman (2018) found that Rwandan migrants in Belgium used instrumental support provided by host country as coping mechanism whereas their counterparts in Finland engage in substance use as a 
strategy. The difference in the use of coping methods may account for why Rwandan migrants in Belgium were more satisfied compared to those in Finland (Banyanga et al., 2018). However, the study demonstrated that religious coping was not used in dealing with stress within either of the two countries.

In a qualitative study examining the coping strategies of undocumented migrants in the UK, selected participants reported the use of different coping strategies (Bloch, Sigona, \& Zetter, 2009). For example, one participant reported the use of planning in overcoming the challenges associated with illegal status by putting relevant strategies in place to evade police arrest. Others reported that they use religious coping (i.e., asking God to provide strength) to overcome the depressive state experienced as an undocumented immigrant when they initially arrived in the UK. In others words, religious affiliation remains a "surviving guide" through praying and studying the bible. Another participant seems relieved from stress through comforting words and advice (i.e., emotional support) received from other immigrants who have long been on illegal status since arrival in the UK. In addition, some participants were observed to utilize positive reframing by hoping that their present predicaments will improve with time and that as human beings they still possess some rights even though they lack legal status. Maintaining links with family back at home (emotional support), drinking excessive alcohol (substance use), milk and yogurt, and watching TV are others ways of coping with the restrictions associated with illegal status. Further, humor was also utilized by participants. This involved converting their present predicaments into adventure and fun. Overall, all participants reported that the best strategy of coping as a migrant remains getting documented.

In a similar way, Van Bortel, Martin, Anjara, and Nellums (2019) identified religion (i.e., prayer, singing, studying religious text and attending church services), social support, maintaining positive thoughts (positive reframing) and creating time for oneself (which include engaging in leisure, taking enough sleep, and being relaxed and calm) as adaptive way of coping with migration stressors. In addition, DeFreece (2006) found religion, listening to music, substance use, surfing and social networking as coping strategies adopted by sub-Saharan African migrants in Morocco. In the study, listening to music was found to be more recurrently used in coping whereas the consequence of using alcohol was found to be very debilitating in terms of preventing victims from getting jobs and having poor memory.

In a study carried out among a sample of returnee Ethiopian migrants in Middle East countries, Zewdu and Suleyiman (2018) reported that social support, problem solving and avoidance coping were employed in dealing with migration stressors. Problem solving coping mechanisms assumed greater importance among these migrants. In Vaughn and Roesch's (2003) study, planning, religion, active coping, positive reinterpretation, emotional venting, active coping and emotional support were identified as coping mechanisms of Latino immigrants in the United States. The study, in addition, found out that these coping methods were positively associated with both physical and mental health outcomes. 


\section{A Multifaceted Picture}

All in all, one can summarize that the picture is multifaceted. Yes, the 'healthy immigrant' proposition holds for African migrants as well, because in basic terms one can still say that the strongest and fittest, those with most resources of various kinds endeavor in undertaking the sojourn. However, this general rule is undermined, camouflaged or even extinguished when one looks at forced migration, at refugees fleeing war-zones. Even if such migrants arrive in their countries of destination in a relieved or even happy mood, such sentiments quickly vanish for a multitude of reasons. First and foremost, African migrants to Europe are what is sometimes called a visible minority, they differ from the autochthonous population by skin color and by many other habitual criteria. Plainly put, they are met with distrust, to say the least.

Whether under these circumstances, migrants develop mental health problems depends once again on a multitude of personal and contextual reasons. Migrants who had to live under gruesome conditions in their homelands are obviously more at risk than those who lived under hardship but did not suffer from violence of any sort. Mental health problems can — rarely acknowledged by migration research—develop during the migratory trajectory itself, which is often a prolonged life-phase of harassment of different sorts. Very much depends on where refugees land in Europe, for example in a country used to people of color or in a country that has rarely seen African immigration in its history. Whether an individual develops mental health problems certainly is not only a question of homeland or destination contexts, but also has roots in personal histories and genetic dispositions. Value preferences, personality traits play a role, and, more importantly, people's pre-migration life history. At the same time, it seems that receiving countries often enhance mental health problems among immigrants by keeping them in adverse life circumstances, inducing considerable amounts of post-migration stress, offering little to no organized social support, in other words, no hope.

This bleak summary makes it obvious that a study of African migrants to Europe has to encompass several receiving countries: Contexts matters! Also, both premigration and post-migration stress need detailed attention. Needless to say, mental health problems must be assessed in detail. The subsequently reported study sets out to fulfill all sketched demands. However, before we offer details on the conducted study, pre-, mid-, and post-migrations life circumstances of Africans sojourning to Europe need more precise attention.

Take a journey into the things which you are carrying, the known-not into the unknown - into what you already know; your pleasures, your delights, your despairs, your sorrows. Take a journey into that, that is all you have (Jiddu Krishnamurti) ${ }^{3}$

\footnotetext{
${ }^{3}$ https://www.azquotes.com/quote/606800ttps://me.me/i/sometimes-you-just-have-to-stop-beingscared-and-just-16733345. Accessed April 3, 2020.
} 


\section{References}

Afulani, P. A., Torres, J. M., Sudhinaraset, M., \& Asunka, J. (2016). Transnational ties and the health of sub-Saharan African migrants: The moderating role of gender and family separation. Social Science and Medicine, 168, 63-71. https://doi.org/10.1016/j.socscimed.2016.09.009.

Agyekum, B., \& Newbold, B. K. (2016). Religion/spirituality, therapeutic landscape and immigrant mental wellbeing amongst African immigrants to Canada. Mental Health, Religion and Culture, 19(7), 674-685. https://doi.org/10.1080/13674676.2016.1225292.

Ahmed, S. (2017). Acculturative strain and emotional distress among Iraqi refugees resettled in the United States. Alliant International University.

Ahmed, S., \& Rasmussen, A. (2019). Changes in social status and post migration mental health among West African immigrants. American Journal of Orthopsychiatry. https://doi.org/10.1037/ ort0000419.

Ambugo, E., \& Yahirun, J. (2016). Remittances and risk of major depressive episode and sadness among new legal immigrants to the United States. Demographic Research, 34, 243-258. Retrieved from https://www.demographic-research.org/volumes/vol34/8/34-8.pdf.

Arrey, A. E., Bilsen, J., Lacor, P., \& Deschepper, R. (2016). Spirituality/religiosity: A cultural and psychological resource among sub-Saharan African migrant Women with HIV/AIDS in Belgium. PLoS ONE, 11(7). https://doi.org/10.1371/journal.pone.0159488.

Ataca, B. (1996). Psychological and sociocultural adaptations of Turkish immigrants, Canadians, and Turks. Paper presented at the 13th Congress of the International Association for CrossCultural Psychology, Montreal, Canada, July.

Ba, I., \& Bhopal, R. S. (2017). Physical, mental and social consequences in civilians who have experienced war-related sexual violence: a systematic review (1981-2014). Public Health, 142, 121-135. https://doi.org/10.1016/j.puhe.2016.07.019.

Banyanga, J. D., Björkqvist, K., Akademi, A., \& Österman, K. (2018). Coping strategies and psychological interventions among traumatized African Migrants in the Western World: A Comparison between Rwandans in Finland and Belgium. European Journal of Social Sciences Education and Research, 12(1), 84-93. https://doi.org/10.26417/ejser.v12i1.p84-92.

Barber, S., \& Ramsay, L. (2017). Refugees: The new global issue facing teachers in Canada. Paper presented at the Global Conference on Education and Research (GLOCER 2017). Retrieved from https://scholarcommons.usf.edu/cgi/viewcontent.cgi?article=1009\&context=anaheipublishing.

Basheti, I. A., Obeidat, N. M., \& Reddel, H. K. (2017). Effect of novel inhaler technique reminder labels on the retention of inhaler technique skills in asthma: a single-blind randomized controlled trial. NPJ Primary Care Respiratory Medicine, 27(9), 1-7. https://doi.org/10.1038/s41533-017$0011-4$.

Benedek, D. M., \& Wynn, G. H. (2011). Clinical manual for management of PTSD. Britain: American Psychiatric Publishing Inc.

Blackford, J., Street, A., \& Parsons, C. (1997). Breaking down language barriers in clinical practice. Contemporary Nurse, 6, 15-21.

Bloch, A., Sigona, N., \& Zetter, R. (2009). No right to dream: The social and economic lives of young undocumented migrants in Britain. London: Paul Hamlyn Foundation.

Bogic, M., Njoku, A., \& Priebe, S. (2015). Long-term mental health of war-refugees: a systematic literature review. BMC International Health and Human Rights, 15, 29. https://doi.org/10.1186/ s12914-015-0064-9.

Brooke, H. L., Talbäck, M., Hörnblad, J., Johansson, L. A., Ludvigsson, J. F., Druid, H., et al. (2017). The Swedish cause of death register. European Journal of Epidemiology, 32(9), 765-773. https:// doi.org/10.1007/s10654-017-0316-1.

Bryant, R. A., Edwards, B., Creamer, M., O’Donnell, M., Forbes, D., Felmingham, K. L., et al. (2018). The effect of post-traumatic stress disorder on refugees' parenting and their children's mental health: A cohort study. The Lancet-Public Health, 3(5), e249-e258. 
Bustamante, L. H. U., Cerqueira, R. O., Leclerc, E., \& Brietzke, E. (2018). Stress, trauma, and posttraumatic stress disorder in migrants: a comprehensive review. Brazilian Journal of Psychiatry, 40, 220-225. https://doi.org/10.1590/1516-4446-2017-2290.

Cengiz, T., Ergun, D., \& Cakici, E. (2019). Posttraumatic stress disorder, posttraumatic growth and psychological resilience in Syrian refugees, Hatay, Turkey. Anatolian Journal of Psychiatry, 20(3), 269-276. https://doi.org/10.5455/apd.4862.

Chen, W., Hall, B. J., Ling, L., \& Renzaho, A. M. N. (2017). Pre-migration and post-migration factors associated with mental health in humanitarian migrants in Australia and the moderation effect of post-migration stressors: findings from the first wave data of the BNLA cohort study. The Lancet Psychiatry, 4(3), 218-229. https://doi.org/10.1016/S2215-0366(17)30032-9.

Comino, E. J., Silove, D., Manicavasagar, V., Harris, E., \& Harris, M. F. (2001). Agreement in symptoms of anxiety and depression between patients and GPs: the influence of ethnicity. Family Practice, 18(1), 71-77.

Craig, T., Jajua, P. M., \& Warfa, N. (2009). Mental health care needs of refugees. Psychiatry, 8(9), 351-354. https://doi.org/10.1016/j.mppsy.2009.06.007.

Crea, T. M., Calvo, R., \& Loughry, M. (2015). Refugee health and wellbeing: Differences between urban and camp-based environments in sub-Saharan Africa. Journal of Refugee Studies, 28(3), 319-330. https://doi.org/10.1093/jrs/fev003.

Daphe, J. C. \& Ferszt, G. G. (2019). Migration experiences of Sierrra Leoneans. Journal of Cultural Diversity, 26(1), 38-45. Retrieved from https://www.questia.com/library/journal/1P42201635767/migration-experiences-of-sierra-leoneans.

De Genova, N. (2018). The "migrant crisis" as racial crisis: Do Black lives matter in Europe? Ethnic and Racial Studies, 41(10), 1765-1782.

Doherty, C. (2015). Trauma and the conscript of the South African border war. English in Africa, 42(2), 25-56. https://doi.org/10.4314/eia.v42i2.2.

Dorchin-Regev, S., \& Slonim-Nevo, V. (2019). Sorrow shared is halved? War trauma experienced by others and mental health among Darfuri asylum seekers. Psychiatry Research, 273, 475-480.

Duggleby, W., Ploeg, J., McAiney, C., Fisher, K., Swindle, J., Chambers, T., et al. (2017). Study protocol: pragmatic randomized control trial of an internet-based intervention (My tools 4 care) for family carers. BMC Geriatrics, 17(1), 181. https://doi.org/10.1186/s12877-017-0581-6.

Dwivedi, R., O’Donnell, M., \& Jankowski, K. (2019). Immigrant and refugee adolescent care: Challenges and opportunities. In L. Barkley, M. Svetaz, \& V. Chulani (eds.), Promoting Health Equity Among Racially and Ethnically Diverse Adolescents (pp. 189-202). Cham, Switzerland: Springer. 10.1007\%2F978-3-319-97205-3_14.

Falah-Hassani, K., Shiri, R., Vigod, S., \& Dennis, C. L. (2015). Prevalence of postpartum depression among immigrant women: A systematic review and meta-analysis. Journal of Psychiatric Research, 70, 67-82. https://doi.org/10.1016/j.jpsychires.2015.08.010.

Fernando, S. (1993). Racism and xenophobia. Innovation: The European Journal of Social Science Research, 6(1), 9-19. https://doi.org/10.1080/13511610.1993.9968330.

Fung, K., \& Guzder J. (2018) Canadian immigrant mental health. In D. Moussaoui, D. Bhugra \& Ventriglio A. (eds), Mental health and illness in migration (pp. 1-21). Singapore: Springer. https://doi.org/10.1007/978-981-10-0750-7_11-1.

Furnham, A., \& Shiekh, S. (1993). Gender, generational and social support correlates of mental health in Asian immigrants. International Journal of Social Psychiatry, 39(1), 22-33. https://doi. org/10.1177/002076409303900103.

García, F. E., Barraza-Peña, C. G., Wlodarczyk, A., Alvear-Carrasco, M., \& Reyes-Reyes, A. (2018). Psychometric properties of the Brief-COPE for the evaluation of coping strategies in the Chilean population. Psicologia: Reflexão e Crítica, 31(22), 1-11. https://doi.org/10.1186/s41155-0180102-3.

Glen, M., Onsando, G., \& Kearney, J. (2015). Education pathways for humanitarian background refugees in Southeast QLD. Retrieved from https://www.academia.edu/29136768/Education_Pat hways_for_Humanitarian_Background_Refugees_in_Southeast_QLD_Focus_on_Logan_Com munity. 
Gorman, D., Brough, M., \& Elvia, R. (2003). How young people from culturally and linguistically diverse backgrounds experience mental health: Some insights for mental health nurses. International Journal of Mental Health Nursing, 12(3), 194-202.

Ottisova L., Hemmings, S., Howard, L. M., Zimmerman, C., \& Oram, S. (2016). Prevalence and risk of violence and the mental, physical and sexual health problems associated with human trafficking: an updated systematic review. Epidemiology and Psychiatric Science, 25, 317-341. https://doi.org/10.1017/s2045796016000135.

Horlings, A., \& Hein, I. (2018). Psychiatric screening and interventions for minor refugees in Europe: an overview of approaches and tools. European Journal of Pediatrics, 177(2), 163-169. https://doi.org/10.1007/s00431-017-3027-4.

Ibrahim, H., \& Hassan, C. Q. (2017). Post-traumatic stress disorder symptoms resulting from torture and other traumatic events among Syrian Kurdish refugees in Kurdistan Region, Iraq. Frontiers in Psychology, 8, 241. https://doi.org/10.3389/fpsyg.2017.00241.

Idemudia, E. S. (2018). A path analysis for the prediction of Afroxenoglossophobia in South Africa. Gender and Behaviour, 16(3), 11839-11853. Retrieved from https://journals.co.za/content/jou $\mathrm{rnal} / 10520 / \mathrm{EJC}-135710 \mathrm{ab} 8 \mathrm{f}$.

Idemudia, E. S., \& Boehnke, K. (2005). Globalisierung, Afrika and afrikanische Immigranten in Deutschland: Ein empirischer Bericht. In A. Groh (Ed.), be-WEG-ung: Akademische Perspektiven auf Reisen und Ortswechsel (pp. 49-69). Berlin: WEIDLER Buchverlag.

Idemudia, E. S., \& Boehnke, K. (2010). I'm an alien in Deutschland: A quantitative mental health case study of African Immigrants in Germany. Frankfurt, Germany: Peter Lang Publishers.

Idemudia, E. S., John, W. K., \& Wyatt, G. E. (2013a). Migration challenges among Zimbabwean refugees before, during and after arrival in South Africa. Journal of Injury Violence Research, 5(1), 17-27. https://doi.org/10.5249/jivr.vSi1.185.

Idemudia, E. S., Madu, S. N., Wyattt, G. E., \& Williams, J. K. (2013b). Trauma and posttraumatic stress among Zimbabwean refugees in South Africa Life Sci J, 10(3), 2397-2407 (ISSN: 10978135). Retrieved from http://www.lifesciencesite.com.

Idemudia, E. S., Williams, J. K., Boehnke, K., \& Wyatt, G. E. (2013c). Gender differences in trauma and posttraumatic stress symptoms among displaced Zimbabweans in South Africa. Journal of Traumatic Stress Disorders and Treatment, 2(3), 1-11. https://doi.org/10.4172/2324-8947.100 0110.

Idemudia, E. S., Williams, J. K., Madu, S. N., \& Wyatt, G. E. (2013). Trauma exposures and posttraumatic stress among Zimbabwean refugees in South Africa. Life Science Journal, 25(10), 349. Retrieved from https://www.ncbi.nlm.nih.gov/pmc/articles/PMC4222742/.

Jannesari, S., Molyneaux, E., \& Lawrence, V. (2019). What affects the mental health of people seeking asylum in the UK? A narrative analysis of migration stories. Qualitative Research in Psychology. https://doi.org/10.1080/14780887.2019.1581311.

Jefferies, L. R. (2018). Population health needs analysis-UK asylum seekers and refugees. Links to Health and Social Care, 3(2), 84-108. https://doi.org/10.24377/LJMU.lhsc.vol3iss2article215.

Kagaba, T. (2018). Gender boundary negotiation within the US immigrant/refugee resettlement: How transnational bridge-building matters (Doctoral thesis, University of Louisville). Retrieved from https://pdfs.semanticscholar.org/9d18/47d8e7a4d1308c55fc467156195184ae6f16.pdf.

Kaoutar El Maazouz, A., \& Scruby, L. (2019). Posttraumatic stress disorder among refugees. The Journal for Nurse Practitioners, 15(5), 339-342. https://doi.org/10.1016/j.nurpra.2019.02.018.

Kashyap, S., Page, A. C., \& Joscelyne, A. (2019). Post-migration treatment targets associated with reductions in depression and PTSD among survivors of torture seeking asylum in the USA. Psychiatry Research, 271, 565-572. https://doi.org/10.1016/j.psychres.2018.12.047.

Khawaja, N, G., Ibrahim, O., \& Schweitzer, R. D. (2017). Mental wellbeing of students from refugee and migrant backgrounds: The mediating role of resilience. School Mental Health, 9(3), 284-293. https://doi.org/10.1007/s12310-017-9215-6.

Ki, E.-Y., \& Jang, J. Y. (2018). Social support and mental health: An analysis of online support forums for Asian immigrant women. Journal of Asian Pacific Communication, 28(2), 226-250. https://doi.org/10.1075/japc.28.2. 
Kovinthan, T. (2016). Learning and teaching with loss: Meeting the needs of refugee children through narrative inquiry. Diaspora, Indigenous, and Minority Education, 10(3), 141-155. https:// doi.org/10.1080/15595692.2015.1137282.

Lazarus, R. S., \& Folkman, S. (1984). Stress, appraisal, and coping. New York, NY: Springer Publishing.

Le, L., Morina, N., Schnyder, U., Schick, M., Bryant, R. A., \& Nickerson, A. (2018). The effects of perceived torture controllability on symptom severity of posttraumatic stress, depression and anger in refugees and asylum seekers: A path analysis. Psychiatry Research, 264, 143-150. https://doi.org/10.1016/j.psychres.2018.03.055.

Levecque, K., Lodewyckx, I., \& Vranken, J. (2007). Depression and generalised anxiety in the general population in Belgium: A comparison between native and immigrant groups. Journal of Affective Disorders, 97(1-3), 229-239.

Levecque, K., \& Van Rossem, R. V. (2015). Depression in Europe: Does migrant integration have mental health payoffs? A cross-national comparison of 20 European countries. Ethnicity \& Health, 20(1), 49-65. https://www.ncbi.nlm.nih.gov/pubmed/24517205.

Lincoln, A. K., Lazarevic, V., White, M. T., \& Ellis, B. H. (2016). The impact of acculturation style and acculturative hassles on the mental health of Somali adolescent refugees. Journal of Immigrant and Minority Health, 18(4), 771-778. https://doi.org/10.1007/s10903-015-0232-y.

Littlewood, R., \& Lipsedge, M. (1989). Aliens and Alienists: Ethnic minorities and psychiatry. London: Unwin Hyman Ltd.

LoGiudice, D., Hassett, A., Cook, R., Flicker, L., \& Ames, D. (2001). Equity of access to a memory clinic in Melbourne? Non-English-speaking background attenders are more severely demented and have increased rates of psychiatric disorder. International Journal of Geriatric Psychiatry, 16, 327-34. https://doi.org/10.1002/gps.346.abs.

Mabeya, D. O. (2017). An ethnographic inquiry! Conceptualizing the integration experiences of the Sudanese refugee lost boys in the Greater Kansas City Area using assimilation paradigms. Journal of Humanities and Social Science, 22(5), 83-94. https://doi.org/10.9790/0837-220506 8394.

Marshall, J. (1995). Gender and management: A critical review of research. British Journal of Management, 6, S53-S62.

Martinez, O., Wu, E., Sandfort, T., Dodge, B., Carballo-Dieguez, A., Pinto, R., ..., et al. (2015). Evaluating the impact of immigration policies on health status among undocumented immigrants: A systematic review. Journal of Immigrant and Minority Health, 17(3), 947-970. https://doi.org/ 10.1007/s10903-013-9968-4.

Matlin, S., Depoux, A., Schutte, S., Fiahault, A., \& Saso, L. (2017). Migrations and refugees' health: towards an agenda of solutions. Public Health Reviews, 39(27), 1-55. https://doi.org/10.1185/ s40985-0180104-9.

McCann, T. V., Mugavin, J., Renzaho, A., \& Lubman, D. I. (2016). Sub-Saharan African migrant youths' help-seeking barriers and facilitators for mental health and substance use problems: A qualitative study. BMC Psychiatry, 16(275). https://doi.org/10.1186/s12888-016-0984-5.

McDonald, S. E. I., Hyojin, Green, K. E., Luce, B., \& Denise, B. (2019). Comparing factors models of Posttraumatic stress disorder (PTSD) with Somali refugee youth in Kenya: An item response theory analysis of the PTSD Checklist-Civilian version. Traumatology, 25(2), 104-114. https:// doi.org/10.1037/trm0000175.

Melamed, S., Chernet, A., Labhardt, N. D., Probst-Hensch, N., \& Pfeiffer, C. (2019). Social resilience and mental health among Eritrean asylum-seekers in Switzerland. Qualitative Health Research, 29(2), 222-236. https://doi.org/10.1177/1049732318800004.

Meyer-Weitz, A., Asante, K. O., \& Lukobeka, B. J. (2018). Healthcare service delivery to refugee children from the Democratic Republic of Congo living in Durban, South Africa: A caregivers' perspective. BMC Medicine, 16, 163. https://doi.org/10.1186/s12916-018-1153-0.

Mhlongo, M. D., Tomita, A., Thela, L., Maharaj, V., \& Burns, J. K. (2018). Sexual trauma and posttraumatic stress among African female refugees and migrants in South Africa. South African Journal of Psychiatry, 24(1), 1-4. https://doi.org/10.4102/sajpsychiatry.v24.i0.1208. 
Minihan, S., Liddell, B. J., Byrow, Y., Bryant, R. A., \& Nickerson, A. (2018). Patterns and predictors of posttraumatic stress disorder in refugees: A latent class analysis. Journal of Affective Disorders, 232, 252-259. https://doi.org/10.1016/j.jad.2018.02.010.

Mulugeta, M. (2019). Community Organizing as a Vehicle to Promote Public Health in Clarkston, GA: A Literature Review \& Case Study of Georgia Refugee Health and Mental Health (Master's thesis, Georgia State University, Atlanta). Retrieved from https://scholarworks.gsu.edu/cgi/vie wcontent.cgi?article $=1111 \&$ context=iph_capstone.

Nakash, O., Nagar, M., Shoshani, A., \& Lurie, I. (2015). The association between acculturation patterns and mental health symptoms among Eritrean and Sudanese asylum seekers in Israel. Cultural Diversity and Ethnic Minority Psychology, 21(3), 468-476. https://doi.org/10.1037/a00 37534.

Nakash, O., Nagar, M., Shoshani, A., \& Lurie, I. (2017). The association between perceived social support and posttraumatic stress symptoms among Eritrean and Sudanese male asylum seekers in Israel. International Journal of Culture and Mental Health, 10(3), 261-275. https://doi.org/ 10.1080/17542863.2017.1299190.

Nel, M. (2018). Pentecostal prophecy: A pastoral response to the challenges of South African Xenophobia. Conspectus: The Journal of the South African Theological Seminary, 2018 (Special Edition 2), 20-39. Retrieved from https://journals.co.za/content/journal/10520/EJC-15642f0f08.

Neto, F., \& Guse, T. (2018). Predictors of mental health among Angolan migrants living in Portugal. International Journal of Migration, Health and Social Care, 14(2), 146-159. https://doi.org/10. 1108/IJMHSC-03-2017-0006.

Ogunbajo, A., Anyamele, C., Restar, A. J., Dolezai, C., \& Sandfort, T. G. M. (2018). Sub-stance use and depression among recently migrated African gay and bisexual men living in the United States. Journal of Immigration and Minority Health, 1-9. https://doi.org/10.1007/s10903-0180849-8.

Pannetier, J., Lert, F., Jauffret Roustide, M., \& du Loû, A. D. (2017). Mental health of sub-Saharan African migrants: The gendered role of migration paths and transnational ties. SSM-Population Health, 3, 549-557. https://doi.org/10.1016/j.ssmph.2017.06.003.

Paredes, M. (2017). Supporting mental health of immigrant communities. Mental Health of America. Retrieved from https://www.mentalhealthamerica.net/sites/default/files/1245p2\%20Paredes.pdf.

Plener, P. L., Groschwitz, R. C., Brähler, E., Sukale, T., \& Fegert, J. M. (2017). Unaccompanied refugee minors in Germany: attitudes of the general population towards a vulnerable group. European Child Adolescent Psychiatry, 26, 733-742. https://doi.org/10.1007/s00787-0170943-9.

Polonsky, M. J., Ferdous, A. S., Renzaho, A. M. N., Waters, N., \& McQuilten, Z. (2018). Factors leading to health care exclusion among African refugees in Australia: The case of blood donation. Journal of Public Policy and Marketing, 37(2), 306-326. https://doi.org/10.1177/074391561881 3115.

Pratchett, L. C., Pelcovitz, M. R., \& Yehuda, R. (2010). Trauma and violence: Are women the weaker sex? Psychiatric Clinics of North America, 33(2), 465-474.

Priebe, S., Giacco, D., \& El-Nagib. R. (2016). Public health aspects of mental health among migrants and refugees: a review of the evidence on mental health care for refugees, asylum seekers and irregular migrants in the WHO European Region. Copenhagen: WHO Regional Office for Europe. Retrieved from http://www.euro.who.int/_data/assets/pdf_file/0003/317622/ HEN-synthesis-report-47.pdf?ua=1.

Purewal, R. (2018). Mental ill health in adult refugees: A literature study (Doctoral thesis, Upssala University, Sweden). Retrieved from https://pdfs.semanticscholar.org/6926/6f8fafe8f24b9f5cf0 bd0752ae3adca278a9.pdf.

Reavell, J., \& Fazil, Q. (2017). The epidemiology of PTSD and depression in refugee minors who have resettled in developed countries. Journal of Mental Health, 26(1), 74-83. https://doi.org/ $10.1080 / 09638237.2016 .1222065$. 
Salas-Wright, C. P., Vaughn, M. G., Goings, T. C., Miller, D. P., Chang, J., \& Schwartz, S. J. (2018). Alcohol-related problem behavior among Latino immigrants in the US: Evidence from a national sample. Addictive Behaviors, 87, 206-213. https://doi.org/10.1016/j.psychres.2018.06.039.

Salfi, N. (2016). An interview-based assessment of access of health care in Philadelphia for undocumented immigrants. Retrieved from https://pdfs.semanticscholar.org/1f3f/13aaaf31dd7df3618f e83f2322bb3da42e54.pdf.

Sapmaz, S. Y., Tannverdi, B. U., Oztürk, M., Gozacaular, O., Ulker, Y., \& Ozkan, Y. (2017). Immigration-related mental health disorders in refugees 5-18 years living in Turkey. Neuropsychiatric Disease and Treatment, 13, 2813-2821. https://doi.org/10.2147/NDT.S150592.

Schick, M., Morina, N., Mistridis, P., Schnyder, U., Bryant, R. A., \& Nikerson, A. (2018). Changes in post-migration living difficulties predict treatment outcome in traumatized refugees. Frontiers in Psychiatry 9, 476. https://doi.org/10.3389/psyt.2018:00476.

Schubert, C. C., Punamäki, R., Suvisaari, J., Koponen, P., \& Castaneda, A. (2019). Trauma, psychosocial factors, and help-seeking in three immigrant groups in Finland. The Journal of Behavioral Health Services \& Research, 46(1), 80-98. https://doi.org/10.1007/s11414-0189587-x.

Shoshani, A., Nakash, O., Zubida, H., \& Harper, R. A. (2016). School engagement, acculturation, and mental health among migrant adolescents in Israel. School Psychology Quarterly, 31(2), 181-197. https://doi.org/10.1037/spq0000133.

Silove, D., Ventevogel, P., \& Rees, S. (2017). The contemporary refugee crisis: An overview of mental health challenges. World Psychiatry, 16, 130-139. https://doi.org/10.1002/wps.20438.

Smit, R., \& Rugunanan, (2015). Transnational forced migration and negotiating emotional wellbeing: The case of women refugees in South Africa. Social Dynamics: A Journal of African Studies, 41(1), 184-203. https://doi.org/10.1080/02533952.2015.1029749.

Staudenmeyer, A., Macciomei, E., Del Cid, M., \& Patel, S. G. (2016). Immigrant youth life stressors. In S. Patel \& D. Reicherter (Eds.), Psychotherapy for immigrant youth (pp. 3-24). Cham, Switzerland: Springer.

Stenmark, H., Catani, C., Neuner, F., Elbert, T., \& Holen, A. (2013). Treating PTSD in refugees and asylum seekers within the general health care system. A randomized controlled multicenter study. Behaviour Research and Therapy, 51, 641-647. https://doi.org/10.1016/j.brat.2013.07.002.

Thapa, S. B., \& Hauff, E. (2005). Psychological distress among displaced persons during an armed conflict in Nepal. Social Psychiatry and Psychiatric Epidemiology, 40(8), 672-679.

Thela, L., Tomita, A., Maharj, V., Mhlongo, M., \& Burns, J. K. (2018). Counting the cost of Afrophobia: Post-migration adaptation and mental health challenges of African refugees in South Africa. Transcultural Psychiatry, 54(5-6), 715-732. https://doi.org/10.1177/1363461517745472.

Thompson, C. T., Vidgen, A., \& Roberts, N. P. (2018). Psychological interventions for Posttraumatic stress disorder in refugees and asylum seekers: A systematic review and meta-analysis. Clinical Psychology Review, 63, 66-79. https://doi.org/10.1016/j.cpr.2018.06.006.

Thomson, M. S., Chaze, F., George, U., \& Guruge, S. (2015). Improving immigrant populations' access to mental health services in Canada: a review of barriers and recommendations. Journal of Immigrant and Minority Health, 17(6), 1895-1905. https://doi.org/10.1007/s10903-015-0175-3.

Tinghög, P., Hemmingsson, T., \& Lundberg, I. (2008). To what extent may the association between immigrant status and mental illness be explained by socioeconomic factors? Social Psychiatry and Psychiatric Epidemiology, 42, 990-996. https://doi.org/10.1007/s00127-007-0253-5.

Toselli, S., Rinaldo, N., Caccialupi, M. G., \& Gualdi-Russo, E. (2018). Psychosocial Indicators in North African Immigrant Women in Italy. Journal of Immigrant and Minority Health, 20(2), 431-440. https://doi.org/10.1007/s10903-017-0562-z.

Turrini, G., Purgato, M., Ballette, F., Nosè, M., Ostuzzi, G., \& Barbui, C. (2017). Common mental disorders in asylum seekers and refugees: umbrella review of prevalence and intervention studies. International Journal of Mental Health Systems, 11(51). https://doi.org/10.1186/s13033-0170156-0. 
United Nations Commission on Human Right. (UNHCR, 2017). Statistical yearbook 2016. https://www.unhcr.org/statistics/country/5a8ee0387/unhcr-statistical-yearbook-2016-16th-edi tion.html.

Uwibereyeho-King, R., Heinonen, T., Uwabor, M., \& Adeleye-Olusae, A. (2017). The psychosocial wellbeing of African Refugees in Winnipeg: Critical stressors and coping strategies. Journal of Immigrant and Refugees Studies, 15(4), 345-365. https://doi.org/10.1080/15562948.2016.118 6770 .

Van Bortel, T., Martin, S., Anjara, S., \& Nellums, L. B. (2019). Perceived stressors and coping mechanisms of female migrant domestic workers in Singapore. PLoS ONE, 14(3), e0210717. https://doi.org/10.1371/journal.pone.0210717.

Van der Ven, E., Veling, W., Tortelli, A., Tarricone, I., Berardi, D., Bourque, F., et al. (2016). Evidence of an excessive gender gap in the risk of psychotic disorder among North African immigrants in Europe: A systematic review and meta-analysis. Social Psychiatry and Psychiatric Epidemiology, 51(12), 1603-1613. https://doi.org/10.1007/s00127-016-1261-0.

Vaughn, A. A., \& Roesch, S. C. (2003). Psychological and physical health correlates of coping in minority adolescents. Journal of Health Psychology, 8, 671-683. https://doi.org/10.1177/135910 53030086002 .

Vega, W. A., Zimmerman, R., Gil, A., Warheit, G., \& Apospori, E. (1993). Acculturative strain theory: Its application in explaining drug use behavior among Cuban and on-Cuban Hispanic youth. In M. DeLaRosa (Ed.), Drug abuse among minority youth: Advances in research and methodology (pp. 144-166). Rockville, MD: NIDA.

Ward, C., \& Chang, W. C. (1997). "Cultural fit": A new perspective on personality and sojourner adjustment. International Journal of Intercultural Relations, 21(4), 525-533. https://doi.org/10. 1016/S0147-1767(97)00023-0.

Whitley, R., Wang, J., Fleury, M., Liu, A., \& Caron, J. (2016). Mental health status, health care utilisation, and service satisfaction among immigrants in Montreal: An epidemiological comparison. The Canadian Journal of Psychiatry, 62(8), 570-579. https://doi.org/10.1177/070674371 6677724.

WHO. (2018a). Health of refugees and migrants: Regional situation analysis, practices, experiences, lessons learned and ways forward. Retrieved from https://www.who.int/migrants/publications/ EURO-report.pdf.

WHO. (2018b). Mental health promotion and mental health care in refugees and migrants: Technical guidance. Retrieved from http://www.euro.who.int/_data/assets/pdf_file/0004/386563/mentalhealth-eng.pdf?ua=1.

Wittig, U., Lindert, J., Merbach, M., \& Brähler, E. (2008). Mental health of patients from different cultures in Germany. European Psychiatry, 23(Supplement 1), 28-35. https://doi.org/10.1016/ S0924-9338(08)70059-2.

Wong, W. C. W., Cheung, S., Miu, H. Y. H., Chen, J., Loper, K. A., \& Holroyd, E. (2017). Mental health of African asylum-seekers and refugees in Hong Kong using the social determinants of health framework. BMC Public Health, 17, 1-9. https://doi.org/10.186/si2889-016-3953-5.

Wong, J. P., Li, A. T., Poon, M. K., \& Fung, K. P. (2013). An exploratory study on the mental health of immigrants, refugees and non-status people living with HIV in Toronto. International Journal of Migration Health and Social Care, 9(3), 122-134. https://doi.org/10.1108/IJMHSC-07-20130026.

Wu, Q., Te, G., Edmond, A., Foster, K., Gatt, J.M., ..., et al. (2018). Acculturation, resilience, and mental health of migrant youth: a cross-country comparative study. Public Health, 162, 63-70. https://doi.org/10.1016/j.puhe.2018.05.006.

Yachouh, R. (2018). A Qualitative Investigation of the Mental Health Needs of Syrian Refugees and Immigrants. (Master's thesis, University of Toronto, Canada). Retrieved from https://tspace.lib rary.utoronto.ca/bitstream/1807/89599/3/Yachouh_Rosemary_201806_MSc_thesis.pdf.

Zewdu, A., \& Suleyiman, M. (2018). Depression and coping mechanism among migrant returnees from Middle East countries in Amhara region, Ethiopia. Health Science Journal, 12(2), 560. https://doi.org/10.21767/1791-809X.1000560. 
Ziersch, A., Due, C., \& Walsh, M. (2018). Discrimination experienced by people from refugee and asylum-seeking backgrounds resettled in South Australia: the implications for health and wellbeing. European Journal of Public Health, 28(suppl_1). https://doi.org/10.1093/eurpub/cky 048.166.

Open Access This chapter is licensed under the terms of the Creative Commons Attribution 4.0 International License (http://creativecommons.org/licenses/by/4.0/), which permits use, sharing, adaptation, distribution and reproduction in any medium or format, as long as you give appropriate credit to the original author(s) and the source, provide a link to the Creative Commons license and indicate if changes were made.

The images or other third party material in this chapter are included in the chapter's Creative Commons license, unless indicated otherwise in a credit line to the material. If material is not included in the chapter's Creative Commons license and your intended use is not permitted by statutory regulation or exceeds the permitted use, you will need to obtain permission directly from the copyright holder.

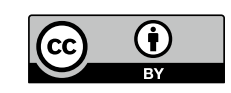

